Type of Article- Original Research Article.

\title{
Consensual Sexual Intercourse among children Vs Current Legal Provisions under POCSO: A Scientific Review with Prospective Quantitative Analytical Study
}

\author{
H. S. Tatiya ${ }^{1}$, A. A. Taware' ${ }^{2}$ H. V. Vaidya ${ }^{3}$, V. T. Jadhav², A. L. Bandgar ${ }^{1}$, S. B. Punpale ${ }^{4}$ \\ ${ }^{1}$ Assistant Professor, ${ }^{2}$ Associate professor, ${ }^{3}$ Senior Resident, Department of Forensic Medicine and Toxicology, \\ BJGMC and SGH, Pune, ${ }^{4}$ Professor, Department of Forensic Medicine and Toxicology, SKNMC, Pune
}

\begin{abstract}
Background: Prevention of Children from Sexual Offences (POCSO) act criminalizes all acts of sexual intercourse and does not differentiate acts of consensual sexual intercourse from provisions of the said act. Aim: To find incidence and demography of victims and accused in cases of consensual sexual intercourse registered as cases of alleged sexual assault under POCSO Material and Method: Current study was conducted at B J Government Medical College Pune on alleged cases of sexual assault brought for examination during November 2015 to September 2017, with cases of female child with history of consensual sexual intercourse being the inclusion criteria. Result: A total of $174(32.58 \%)$ cases of consensual sexual intercourse was examined with the majority being from the age group of 16-17 years (36.78\%). Out of 174 cases, 24 were pregnant. In all only 02 were completely illiterate. Among accused majority were from the age group of 22-24 years (40.23\%). Conclusion: Consensual sexual intercourse among children is known and different entity and should be treated separately from the purview of POCSO, but should also maintain the letter and spirit of the law.
\end{abstract}

Keywords: Consensual sexual intercourse, POCSO, child autonomy, teenage pregnancy.

\section{Introduction}

Historically, child sexual abuse (CSA) has been a hidden problem in India, largely ignored in public discourse and by the criminal justice system. However, the movement, spearheaded by Ministry of Women and Child development, led to the enactment of new legislation called the protection of Children from Sexual Offences (POCSO). ${ }^{1}$

Under POCSO act, the numbers of CSA cases registered for the year 2014 were 8904 which rose to 14,913 in year $2015 .{ }^{2}$ In a shocking revelation, a government-commissioned survey in the year 2005 has found that more than 53 percent of Indian children are subjected to sexual assault, i.e. 4 out of every 10 persons. ${ }^{3}$ A recent report on the census data of 2011 indicated that in India one in six women were married before they were 18 years of age, of which $17.5 \%$ (6.5 million) women had been married within four years before when the census was conducted. ${ }^{4}$ Thus there are possibly 6.5 million (and growing) potential lawsuits, under POCSO. But, all sexual acts described under POCSO, are without exception, considered to be criminal offences if they involve, a 'victim' under the age of 18 years. Adolescence years are the age of exploration and development. In this stage, children develop sexually. Considering all sexual activity, even if they are done with consent, under POCSO they are considered a crime. ${ }^{1}$

Article 12 of United Nations Convention on the Rights of Child (UNCRC) states: "States Parties shall assure to the child who is capable of forming his or her views the right to express those views freely in all matters affecting the child, the views of the child being given due weight in accordance with the age and maturity of child." 5 Thus consensual sexual intercourse of a child becomes a controversial issue for implementation of the POCSO act. $^{1}$ 
Hence present prospective study is conducted to highlight this issue quantitatively, to find the incidence of such cases of consensual sexual intercourse in children and its burden on the existing legal system.

\section{Material and Method}

The present study is a prospective, quantitative, analytical study conducted at B J Government Medical College and Sassoon General Hospitals, Pune from November 2015 to September 2017 after obtaining permission from the institutional ethical committee. All female child cases, victims of alleged sexual assault brought for medical examination of age less than 18 years, who had given the history of voluntary sexual intercourse, were included in the study after obtaining the appropriate and valid consent. All other cases were excluded.

After taking a detailed history from victims and on perusal of supportive documents submitted by investigating authorities, relevant information about consent for sexual intercourse, age of menarche, pregnancy, and educational status were recorded in predesigned proforma. This information was then statistically analyzed using Microsoft excels software and presented in the form of diagrams and tables.

\section{Observation and Result}

During the study period total, 948 victims of alleged sexual assault were brought for medical examination. Out of these $571(60.23 \%)$ were of age less than 18 years and 534 (56.23\%) had given consent for examination.
Medico-legal Update, July-September 2020, Vol.20, No. 3

61

Out of this, $174(32.58 \%)$ cases were included in the present study as per the inclusion criteria. (Diagram 1)

When details of consent given for sexual intercourse were taken into consideration the total 174 (32.58\%) victims mentioned the history of voluntary and consensual sexual intercourse. The majority of them were of age group 16-17(36.78\%) followed by 17 18(29.31\%). The minimum age of menarche was 11 years and the maximum is 16 years with the average age of menarche as 12.7 years. In all 170 cases $(97.70 \%)$ were falling within the age group of 13-18 years. (Table1)

Out of 174 cases, 24 cases $(13.80 \%)$ became pregnant. Amongst these pregnant females majority were from age group $16-17$ years (41.67\%) followed by $17-18$ years $(29.16 \%)$ with percentage within $13-18$ years age group as 100 percent. (Table 2)

Considering educational status 127 (72.99\%) were still studying with the majority being in secondary school (77.95\%) and 45 (25.86\%) had left education with the majority during secondary schooling $(80 \%)$; while only $02(1.15 \%)$ were illiterate and never went to any educational institution. (Table 3)

Demography of the accused in these cases showed that the majority were from the age group of 22-24 years (40.23\%) followed by $25-27$ years $(21.84 \%)$ and $19-21$ years $(20.11 \%)$. In all total $110(63.22 \%)$ individuals were falling within the age group of 16-24 years. (Table4).

\section{Diagram 1: Diagram showing distribution of cases under various sections.}

Table 1: Age-wise distribution of cases of the victim who had voluntary sex

\begin{tabular}{|l|l|l|l|}
\hline Sr. No & Age of victim who had voluntary sex & Number & Percentage $(\mathbf{n}=\mathbf{1 7 4})$ \\
\hline 01 & $12-<13$ & 04 & 02.29 \\
\hline 02 & $13-<14$ & 02 & 01.15 \\
\hline 03 & $14-<15$ & 15 & 08.62 \\
\hline 04 & $15-<16$ & 38 & 21.84 \\
\hline 05 & $16-<17$ & 64 & 36.78 \\
\hline 06 & $17-<18$ & 51 & 29.31 \\
\hline & $\begin{array}{l}\text { Min age of menarche }-11 \text { years and the maximum is 16 years with } \\
\text { mean as } 12.7\end{array}$ & 170 & 97.70 \\
\hline 08 & 13 to $<18$ & 170 \\
\hline
\end{tabular}


Medico-legal Update, July-September 2020, Vol.20, No. 3

Table 2: Age-wise distribution of cases of the victim who had voluntary sex and became pregnant.

\begin{tabular}{|l|l|l|l|}
\hline Sr. No & Age of victim who had voluntary sex and became pregnant & Number & Percentage (n= 24) \\
\hline 01 & $12-<13$ & 00 & 00 \\
\hline 02 & $13-<14$ & 00 & 00 \\
\hline 03 & $14-<15$ & 04 & 16.67 \\
\hline 04 & $15-<16$ & 03 & 12.50 \\
\hline 05 & $16-<17$ & 10 & 41.67 \\
\hline 06 & $17-<18$ & 07 & 29.16 \\
\hline 07 & 13 to $<18$ & 24 & 100 \\
\hline
\end{tabular}

Table 3: Distribution of cases of the victim who had voluntary sex according to education

\begin{tabular}{|c|c|c|c|c|c|}
\hline Sr. No & \multicolumn{2}{|c|}{ Education status of the victim } & Number & \multicolumn{2}{|c|}{ Percentage $(n=174)$} \\
\hline 01 & \multicolumn{2}{|c|}{ Illiterate } & 02 & \multicolumn{2}{|l|}{1.15} \\
\hline \multirow[t]{6}{*}{02} & \multicolumn{2}{|c|}{ Studying } & 127 & \multicolumn{2}{|l|}{72.99} \\
\hline & $\mathbf{A}$ & Primary Studying & 01 & 0.79 & \multirow{5}{*}{$\begin{array}{l}\text { For these values } \\
n=127\end{array}$} \\
\hline & B & Middle Studying & 05 & 3.94 & \\
\hline & $\mathbf{C}$ & Secondary Studying & 99 & 77.95 & \\
\hline & D & Higher secondary studying & 20 & 15.75 & \\
\hline & $\mathbf{E}$ & Degree studying & 02 & 1.57 & \\
\hline \multirow[t]{6}{*}{03} & \multicolumn{2}{|c|}{ Left studying } & 45 & \multicolumn{2}{|l|}{25.86} \\
\hline & $\mathbf{A}$ & Primary left & 00 & 00 & \multirow{5}{*}{$\begin{array}{l}\text { For these values } \\
n=45\end{array}$} \\
\hline & B & Middle left & 03 & 6.67 & \\
\hline & $\mathbf{C}$ & Secondary left & 36 & 80 & \\
\hline & D & Higher secondary left & 05 & 11.11 & \\
\hline & $\mathbf{E}$ & Degree left & 01 & 2.22 & \\
\hline
\end{tabular}


Table 4: Age-wise distribution of accused.

\begin{tabular}{|l|l|l|l|}
\hline Sr. No & Age of accused & Number & Percentage ( $=\mathbf{1 7 4})$ \\
\hline $\mathbf{0 1}$ & $16-18$ & 05 & 2.87 \\
\hline $\mathbf{0 2}$ & $19-21$ & 35 & 20.11 \\
\hline $\mathbf{0 3}$ & $22-24$ & 70 & 40.23 \\
\hline $\mathbf{0 4}$ & $25-27$ & 38 & 21.84 \\
\hline $\mathbf{0 5}$ & $\mathbf{2 8 - 3 0}$ & 23 & 13.22 \\
\hline $\mathbf{0 6}$ & $\mathbf{3 1 - 3 3}$ & 03 & 1.72 \\
\hline $\mathbf{0 7}$ & $16-24$ & 110 & 63.22 \\
\hline $\mathbf{0 8}$ & $25-32$ & 64 & 36.78 \\
\hline
\end{tabular}

Table 5: Age of consent for sexual intercourse in different countries.

\begin{tabular}{|l|l|l|}
\hline Sr. No & Name of country & Age of Consent for Sexual Intercourse \\
\hline 01 & USA- Northern America & 16 years \\
\hline 02 & UK & 16 years \\
\hline 03 & Germany & 14 years \\
\hline 04 & France & 15 years \\
\hline 05 & India & 18 years \\
\hline 06 & Bangladesh & 14 years \\
\hline 07 & Nepal & 16 years \\
\hline 08 & Japan & 13 years \\
\hline 09 & Israel & 16 years \\
\hline 10 & Indonesia & 16 years \\
\hline 11 & China & 14 years \\
\hline 12 & Canada & 16 years \\
\hline 13 & Brazil & 14 years \\
\hline 14 & Singapore & 16 years \\
\hline 15 & Srilanka & 16 years \\
\hline
\end{tabular}




\section{Discussion}

The current study cannot be compared directly, in a quantitative fashion, to other studies done on the subject of Child sexual abuse, as, to the best of our knowledge none of the previous studies have elaborated data regarding cases of consensual sexual intercourse in children.

From the present study, it is very much clear that $32.58 \%$ of cases fall within the category of consensual sexual intercourse and are cases in conflict with provisions of POCSO, and are probably a burden on the legal system as well as on medical profession. Here we wish to quote a case reported by Sujata Aryakar and Aarathi Chandrashekhar, where 15 year old girl willingly eloped with and married a 22 year old man. ${ }^{6}$ In the same case, the Special court judge rejected the notion that the human body of a person under 18 years is the property of the state, whereby it can restrict individual autonomy. While ruling, the judge held that criminalizing such behavior would not serve the purpose of the enactment. ${ }^{1}$ On the other hand, Arya and Chaturvedi pointed out that criminalizing sex below 18 years will prevent the school counselors and doctors to provide safe sex advice or treat the effects of unsafe sexual practice. ${ }^{7}$

Considering the demography of the accused in the present study, it is worth mentioning that the age group 22-24 years was most involved and affected followed by age groups of 25-27 years and 19-21 years. Shocking $63.22 \%$ of individuals were falling within the age group of 16-24 years. This again highlights the issue of the working adult healthy population of the state being victimized of legal provisions of POCSO.

Considering the literacy $72.99 \%$ of affected girls were still studying while $25.86 \%$ had left education. The majority of the population among both groups was from the secondary standards of the school. As adolescent sex education being given primarily for age groups of 10-19 years in India, ${ }^{8}$ current study raises doubt on standards and contents of sex education being imparted to these children.

The incidence of pregnancy among these girls was $13.80 \%$, with the majority were from age group $16-17$ years $(41.67 \%)$ followed by $17-18$ years $(29.16 \%)$, incorporating $100 \%$ within 13 to 18 years of age.
Complications arising from pregnancy and unsafe abortions are a leading cause of death among women aged 15-19 years, with 20\% of the group experiencing child before 17 years of age, with pregnancies often closely spaced. ${ }^{9}$ This now raises the issue of awareness about outcomes of teenage pregnancy in these age groups and again questions the methodologies adapted to educate these girls under sex education.

Madras High Court in a present ruling in June 2018 stated, "Any consensual sex after the age of sixteen or bodily contact or alleged acts could be excluded from the rigorous provisions of POCSO act and sexual assault could be tried under more liberal provisions which can be introduced in the act, differentiating sexual assault and teenage relationship." Judge further observed, "In cases where age of girl is below 18 years, even though she is capable of giving consent, being mentally matured, unfortunately, the provisions of POCSO act get attracted, if such a relationship transcends beyond platonic limits, catching up with the so called offender of sexual assault, warranting a severe imprisonment of seven/ten years." 10

This thus raises the question of criteria evolved for determination of the age of consent for sexual intercourse. We could not find any scientific guidelines on which maturity of a girl can be decided concerning the age at which she can give consent for sexual intercourse. Secondly raising the age of consent for sexual intercourse from 16 years to 18 years does not seem to depend on any scientific measures but it merely seems to be the result of public outcry and political pressure. ${ }^{11}$ Surprisingly different countries have different ages for the consent of sexual intercourse. (Table 5) ${ }^{12}$

The letter and spirit of law, which defines a child as anyone less than 18 years of age, is to protect children from sexual abuse, but at the same time, there is need of amendment in POCSO concerning cases of consensual sexual intercourse, again to protect these tender aged adolescent lovers and to respect child autonomy. There is also a need to change or to vigilantly monitor, contents, methodology and standards of sex education in adolescents. On the other hand, scientific principles should be laid down simultaneously, to determine the appropriate age of consent for sexual intercourse considering physical, social, sexual, and psychological 
parameters.

\section{Conclusion}

Cases of consensual sexual intercourse in the present study accounted $32.58 \%$ of the population with the majority from age group of 16-17 years (36.78\%), while majority of accused falling within age group of 22-24 years $(40.23 \%)$, elaborating need to understand and differentiate consensual sexual intercourse of child from provisions of POCSO.

\section{Conflict of Interest: Not any}

\section{Source of funding: Not any}

Ethical Clearance: Obtained.

\section{References}

1. Belur J, Singh BB. Child sexual abuse and the law in India: a commentary. Crime Science. 2015; 4(1):26. Available from doi: 10.1186/s40163-0150037-2.

2. Government of India. Study on Child Abuse: India 2007. Available from https://resourcecentre. savethechildren.net/library/study-child-abuseindian-2007. [Accessed on $10^{\text {th }}$ December 2019].

3. Government of India. Child violence. Available from http://ncrb.nic.in/StatPublications/CII/ CII2015/FILES/Tables/Additionaltables.24.11.16. pdf. [Accessed on 09 ${ }^{\text {th }}$ December 2019].
4. Shaikh Z (2015).Fact: 1 in 6 Indian women marry under 18. The Indian Express, p.13.

5. Children's and young people's commission Scotland 2018. Article 34. Available from doi: https://www.cypcs.org.uk/rights/uncrcarticles/ article-34. [Accessed on 07th December 2019].

6. Ayarkar S, Chandrasekhar A. Who decides the "best interests" of the child?. Indian Journal of Medical Ethics. 2016;1(3):184-5.

7. Arya Y, Chaturvedi A. Analysis of underreporting of cases of child sexual abuse in India. The World Journal on Juristic Polity.2017.

8. Ismail S, Shajahan A, Sathyanarayana Rao TS, Wylie K. Adolescent sex education in India: Current perspectives. Indian J Psychiatry. 2015;57:333-7.

9. Barua A, Waghmare R, Venkiteswaran S. Implementing reproductive and child health services in rural Maharashtra, India: A pragmatic approach. Reprod Health Matters. 2003;11:140-9.

10. Rajan MC (2019). Age of consent should be lowered to 16, Observes Madras High Court. Hindustan Times, $p .10$.

11. Age of consent. Wikipedia. Available from https://en.m.wikipedia.org/wiki/age_of_consent. [Accessed on 07 ${ }^{\text {th }}$ December 2019].

12. Legal Ages of Consent by country. Available from https://www.ageofconsent/world. [Accessed on 09 ${ }^{\text {th }}$ December 2019]. 